\begin{tabular}{|l|l|l|}
\hline J URNALTEKNKA & \begin{tabular}{l} 
Volume 7 Nomor 2 \\
Oktober 2021 \\
pp $52-61$ \\
Website: $\underline{\text { https://jurnal.sttw.ac.id/index.php/jte }}$ \\
\hline
\end{tabular} \\
\hline
\end{tabular}

\title{
ANALISIS TROUBLESHOOTING SISTEM AC PADA MOBIL TOYOTA GREAT COROLLA TIPE 4A-FE
}

\author{
Rinasa Agistya Anugrah ${ }^{1^{*}}$, Irfan Ari Pamungkas ${ }^{2}$ \\ ${ }^{1}$ Program Studi Teknologi Mesin, Universitas Muhammadiyah Yogyakarta, Yogyakarta, Indonesia \\ ${ }^{2}$ Adnoc Drilling Abu Dhabi National Oil Company, Abu Dhabi, UAE \\ *Emai: rinasaanugrah@umy.ac.id
}

\begin{abstract}
ABSTRAK
Sistem AC pada kendaraan merupakan suatu sistem yang penting dalam kendaraan khususnya mobil. Menjaga kenyamanan pengendara dan penumpang adalah fungsi dari sistem ini. Pemakaian dalam jangka yang lama menyebabkan perlu adanya monitoring dan perbaikan pada sistem tersebut. Terlebih lagi kasus Sistem AC yang terdapat pada Mobil Toyota Great Corolla Tipe 4A-FE yang notabene adalah mobil lawas keluaran tahun 1994 - 1996. Perawatan (maintenance) dan perbaikan (service) adalah metode yang digunakan dalam menangani masalah menurunnya atau rusaknya Sistem AC pada kendaraan. Tentunya langkah perawatan dan perbaikan harus dilakukan dengan kaidah troubleshooting yang benar. Dalam troubleshooting ada istilah diagnosis, yaitu langkah penemuan gejala kerusakan jika ada dan penentuan pemeriksaan untuk menemukan solusi permasalahan yang ada. Pemerikasaan tersebut dapat dilakukan dengan memeriksa komponen - komponen utama dalam Sistem AC menggunakan alat ukur feeler gauge pada kompresor dan multimeter pada kopling magnetik serta evaporator apakah masih berfungsi normal sesuai standar yang ada di dalam buku manual pedoman perawatan dan perbaikan Sistem AC kendaraan. Setelah hal tersebut ditemukan, kemudian langkah perbaikan dapat dilaksanakan. Hasil nilai tahanan koil kopling magnetik diperoleh 3,9 Ohm dan celah kopling magnet diperoleh $0,5 \mathrm{~mm}$. Hasil nilai tahanan pada instalasi blower pada tiga varian kecepatan yaitu posisi low 2,6 $\mathrm{Ohm}$, posisi medium $0,7 \mathrm{Ohm}$, dan posisi high $0 \mathrm{Ohm}$ sedangkan nilai tahanan pada motor blower sebesar $4 \mathrm{Ohm}$. Hasil pengukuran diperoleh masih dalam batas servis atau masih dalam rentang standar berdasarkan buku manual Toyota Great Corolla Tipe 4A-FE. Oleh karena itu tidak ditemukan permasalahan pada sistem AC tersebut dan dapat disimpulkan bahwa kondisi sistem AC pada Mobil Toyota Great Corolla Tipe 4A-FE tersebut masih dalam kondisi normal dan layak untuk digunakan. Tidak dilakukan langkah perbaikan pada Sistem AC ini hanya saja dilakukan perawatan berkala untuk memastikan semua komponen dalam kondisi normal.
\end{abstract}

Kata kunci: sistem AC kendaraan, Toyota Great Corolla 4A-FE, perawatan, perbaikan, troubleshooting.

\section{ABSTRACT}

The AC system in vehicles is an important system in vehicles, especially cars. Maintaining the comfort of the rider and passenger is the function of this system. Long-term use causes the need for monitoring and improvement of the system. Moreover, the case of the AC system found in the Toyota Great Corolla Type 4A-FE which incidentally is an old car from 1994-1996. Maintenance and repair are methods used to deal with the problem of declining or damaged AC systems in vehicles. Of course, maintenance and repair steps must be carried out with the correct troubleshooting rules. In troubleshooting there is a diagnosis term, which is the step of finding symptoms of damage if any and determining the examination to find solutions to existing problems. This inspection can be carried out by checking the main components in the AC system using a feeler gauge on the compressor and a multimeter on the magnetic clutch and evaporator whether they are still functioning normally according to the standards in the manual for the maintenance and repair of the vehicle's AC system. After this is found, then corrective steps can be carried out. The result of the resistance value of the magnetic coupling coil is $3.9 \mathrm{Ohm}$ and the magnetic coupling gap is $0.5 \mathrm{~mm}$. The results of the resistance value in the blower installation at three speed variants are $2.6 \mathrm{Ohm}$ low position, $0.7 \mathrm{Ohm}$ medium position, and $0 \mathrm{Ohm}$ high 
position while the resistance value to the blower motor is 4 Ohm. The measurement results obtained are still within the service limits or still within the standard range based on the Toyota Great Corolla Type 4A-FE manual book. Therefore, no problems were found in the AC system, and it can be concluded that the condition of the AC system on the Toyota Great Corolla Type 4AFE is still in normal condition and suitable for use. No repair steps have been taken on this AC system; only periodic maintenance is carried out to ensure all components are in normal condition.

Keywords: vehicle air conditioning system, Toyota Great Corolla 4A-FE, maintenance, repair, troubleshooting.

\section{PENDAHULUAN}

Sistem Air Conditioner (AC) merupakan salah satu jenis dari konsep sistem refrigerasi (refrigeration system) yang mampu memindahkan panas (kalor) pada suatu benda atau ruangan yang memiliki temperatur lebih rendah ke suatu benda atau ruangan yang memiliki temperatur lebih tinggi. Pemindahan kalor ini bertujuan untuk memberikan kenyamanan pada pengemudi dan penumpang yang ada di dalam kendaraan, baik itu pada kendaraan ringan seperti mobil dan juga alat berat.

Performa atau kinerja sistem AC yang perlu ditingkatkan agar kemampuan dalam menurunkan temperatur hingga temperatur yang dihendaki dalam waktu yang singkat. Hal ini disebut juga dengan kapasitas pendinginan. Oleh karena itu hal ini akan meningkatkan efisiensi sistem AC tersebut. Hal tersebut juga berkaitan dengan meminimalisasi rugi-rugi yang ada sehingga penggunaan energi akan lebih hemat dengan output fungsi sistem AC yang meningkat kualitas kemurnian udara di dalam ruang kabin penumpang dan akurasi kesesuaian temperature kabin untuk kenyamanan penumpang. Seperti penelitian yang telah dilakukan para peneliti yang meneliti analisis sensitivitas konversi energi untuk efektivitas konsumsi energi, kenyamanan termal, dan kualitas udara di dalam kabin mobil [1].

Untuk menjaga performa atau kinerja sistem AC kendaraan, perlu dilakukan maintenance (perawatan) dan service (perbaikan) jika memang perlu diperbaiki. Melalui langkah troubleshooting sistem AC Mobil, perawatan dan perbaikan dapat dilakukan. Dengan melaksanakan pemeriksaan fungsional komponen secara sistematik pada siklus pendinginan dapat mendeteksi masalah atau trouble yang yang ada pada sistem AC [2].

Pemeriksaan fungsional komponen adalah hal yang terpenting dalam menentukan langkah troubleshooting suatu sistem AC. Perkembangan peralatan pendeteksian dan pemeriksaan sistem AC telah dikembangkan demi meningkatkan efektivitas dan akurasi dalam langkah troubleshooting [3]-[5]. Teknologi berbasis IT (Information Technology) digunakan dalam beberapa peralatan tersebut, misalnya adalah pengaplikasian metode scanning pada sistem telemetri pendeteksian kerusakan sistem AC yang memudahkan dalam pengukuran, pemantauan, dan mengurangi hambatan dalam memperoleh informasi [3], [4]. Nilai akurasi dalam pendeteksian dengan menggunakan metode tersebut adalah sebesar 99\% dan lebih baik dibandingkan dengan pemeriksaan secara manual. Selain itu teknologi pengembangan alat pendeteksian untuk troubleshooting juga diterapkan pada sistem AC Alat Berat yang menggunakan komponen utama sistem kontrol berbasis mikrokontroler [5].

Sistem kontrol juga dikembangkan untuk memonitoring kinerja sistem AC kendaraan. Pengembangan sistem kontrol dan monitoring kinerja sistem AC salah satunya adalah pada temperatur pada komponen evaporator dan mampu mengontrol kecepatan fan exhausting (kipas motor DC) secara halus dan responsif [6]. Rancangan dapat membaca akurat suhu evaporator dalam rentang $10^{\circ}-85^{\circ} \mathrm{C}$ dengan tingkat kesalahan 0,5\% [6]. 
Namun, dengan adanya pengembangan teknologi dalam memudahkan langkah troubleshooting dan monitoring kinerja sistem AC perlu adanya landasan keilmuan yang mampu mendasari kemampuan dasar teknisi ataupun peserta didik baik itu diklat maupun pendidikan formal. Banyak lembaga pendidikan khususnya ilmu terapan seperti politeknik dan sekolah vokasi, telah mengupayakan untuk membuat dan menyediakan trainer sistem AC Mobil sebagai media praktik. Trainer atau alat praktik sebagai media praktikum diperlukan di sekolah vokasi [7].

Penjelasan mengenai analisis troubleshooting sistem AC pada kendaraan diperlukan bagi para teknisi maupun calon teknisi agar mereka mampu memahami langkah troubleshooting dengan tepat sesuai dengan logika berpikir akademis yang baik, tidak hanya hafalan, ilmu titen, ataupun dengan metode "trial and error". Oleh karena itu, dalam penelitian ini akan dibahas mengenai analisis troubleshooting sistem AC pada Mobil dengan sampel Toyota Great Corolla Tipe 4A-FE karena mobil dengan pabrikan Toyota merupakan salah satu produsen market leader di segmen pasarnya.

\section{METODE PENELITIAN}

Sebelum membahas metode yang digunakan dalam penelitian ini, perlu dibahas terlebih dahulu alat dan bahan yang digunakan dalam penelitian ini. Alat merupakan peralatan yang dibutuhkan dalam pengukuran dan pengumpulan data. Sedangkan bahan adalah suatu benda, komponen, dan material yang digunakan dalam penelitian ini.

\subsection{Alat}

Peralatan pada penelitian ini adalah yang tertulis di dalam tabel 1 di bawah ini.

Tabel 1. Peralatan Penelitian

\begin{tabular}{cll}
\hline No & \multicolumn{1}{c}{ Nama Alat } & \multicolumn{1}{c}{ Fungsi } \\
\hline 1 & 1 set peralatan dalam toolbox & Peralatan umum \\
2 & Wire stripper & Mengelupas kabel kabel \\
3 & Multimeter & Multi pengukuran \\
4 & Manifold Gauge & Mengukur tekanan \\
5 & Vacuum Gauge & Menukur kevakuman \\
6 & Feeler Gauge & Mengukur kerenggangan \\
7 & Tachometer & Mengukur kecepatan putaran \\
8 & Solder & Untuk memanaskan timah penghubung kabel \\
9 & Pompa Vakum & Mengosongkan sistem AC \\
10 & Tekker 3 Kaki & Untuk melepasakan pulley \\
11 & Voltmeter Indikator & Penunjukan tegangan \\
12 & Voltmeter Gauge & Pengukur Tegangan pada Rangkaian Kelistrikan \\
\hline
\end{tabular}

\subsection{Bahan}

Bahan - bahan pada penelitian ini adalah yang termuat dalam Tabel 2 di bawah ini.

Tabel 2. Bahan Penelitian

\begin{tabular}{clcc}
\hline No & \multicolumn{1}{c}{ Nama Barang } & Spesifikasi/ Tipe & Jumlah \\
\hline 1 & Engine Toyota Great Corolla & 4A-FE & 1 Unit \\
2 & Unit Sistem AC Mobil & Toyota Great Corolla & 1 Unit \\
\hline
\end{tabular}




\subsection{Skema Siklus Sistem AC}

Siklus merupakan suatu proses yang berurutan yang terjadi dari proses awal ke proses akhir kemudian kembali lagi ke proses awal kemudian ke proses akhir lagi yang berulang secara terus menerus ketika suatu sistem tersebut bekerja. Sistem AC memiliki beberapa proses dalam satu siklusnya, mulai dari kompresi, kondensasi, ekspansi aliran, dan evaporasi. Gambar 1 di bawah ini merupakan skema siklus dari sistem AC. Dari gambar tersebut dapat diketahui bahwa sistem AC memiliki lima komponen utama yaitu kompresor, kondensor, receiver/dryer, katup ekspansi, dan evaporator.

Pada Gambar 1, proses yang ditandai oleh no 1 adalah proses penghisapan refrigeran ke dalam kompresor dimana proses ini berada pada tekanan (p) yang rendah yaitu sekitar kurang lebih 3 bar karena mendapat tekanan vakum (tekanan negatif) dari kompresor dan telah melalui katup ekspansi. Temperatur (T) pada kondisi ini juga sangat rendah karena telah melalui evaporator sekitar $5^{\circ} \mathrm{C}$.

Nomor 2 pada Gambar 1 adalah proses refrigeran yang telah melalui proses kompresi di dalam kompresor sehingga tekanan $(\mathrm{p})$ dan temperatur $(\mathrm{T})$ refrigerant meningkat menjadi sangat tinggi yaitu mencapai \pm 18 bar untuk tekanannya dan $70-$ $100^{\circ} \mathrm{C}$ untuk temperaturnya. Pada proses ini refrigeran berada dalam fase gas.

Proses ketiga adalah yang ditunjukkan oleh nomor 3 pada Gambar 1 di bawah dimana fase refrigeran menjadi cair (liquid) atau liquid vapor (mix phase) bertekanan tinggi namun temperaturnya sudah lebih rendah dibandingkan pada titik 2 pada Gambar 1 karena mengalami pelepasan kalor $(\mathrm{Q})$ ke udara atmosfer. Temperaturnya $(\mathrm{T})$ berkisar antara 40 - 50 derajat Celsius. Sedangkan tekanannya (p) hampir sama dengan tekanan saat belum melalui kondensor, hanya mengalami sedikit penurunan atau \pm 17 bar.

Setelah melewati kondensor, refrigerant akan melalui receiver/ dryer yang berfungsi sebagai penyaring kotoran dan kandungan air yang terdapat pada refrigerant. Pada titik nomor 4 (Gambar 1) setelah refrigerant melalui receiver/ dryer, ia sepenuhnya berfase cair (liquid) dengan tekanan ( $\mathrm{p}$ ) dan temperatur $(\mathrm{T}$ ) yang masih sama dengan saat keluar dari kondensor.

Refrigeran kemudian dialirkan melalui katup ekspansi (expansion valve) untuk menurunkan tekanannya sehingga temperaturnya menjadi rendah hingga \pm 4 bar dengan cara mengabutkan refrigeran tersebut. Proses ini juga disebut sebagai proses throttling. Pada proses ini entalpinya konstan (isenthalpic) maka disebut juga sebagai polytropic. Setelah melaui katup ekspansi (proses nomor 5 pada Gambar 1), refrigeran menuju ke evaporator dimana temperatur (T) refrigeran menjadi sangat rendah sebesar $\pm 10^{\circ} \mathrm{C}$ dan menurun terus hingga $\pm 5^{\circ} \mathrm{C}$ saat keluar dari evaporator. Di dalam evaporator terjadi penyerapan kalor (Q) dari kabin pengemudi dan penumpang, kemudian proses dilanjutkan Kembali pada proses nomor 1 dan seterusnya secara berurutan kembali terjadi berulang-ulang. Hal ini yang dinamakan sebagai siklus sistem AC kendaraan. 


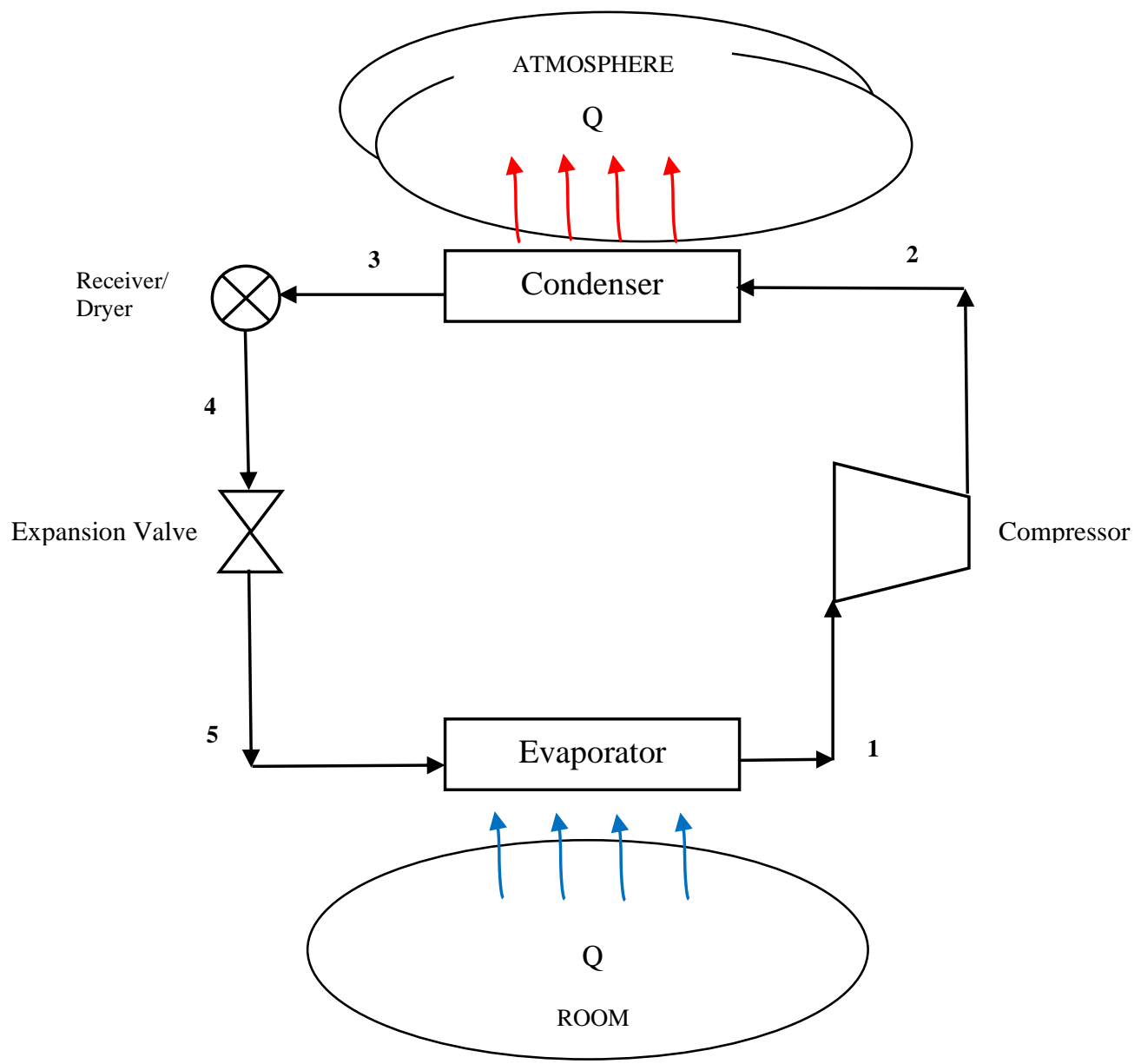

Gambar 1. Skema Siklus Sistem AC

Pada sistem AC kendaraan perlu dilakukan perawatan berkala dan jika terjadi kerusakan maka harus dilakukan perbaikan. Kegiatan ini dilakukan untuk menjaga performa Sistem AC agar selalu dalam kondisi yang terbaik.

\subsection{Rangkaian Sistem Kelistrikan AC}

Di dalam sistem AC kendaraan terdapat sistem yang mengontrol kinerja sistem agar berjalan dengan sebagaimana mestinya dengan baik. Sistem ini dinamakan sistem kelistrikan AC. Dalam sistem kelistrikan AC tentunya terdapat wiring diagram atau diagram rangkaian kelistrikan yang menggambarkan dan menjelaskan prinsip kerja pengontrolan sistem AC. Gambar 2 di bawah ini merupakan rangkaian sistem kelistrikan AC pada kendaraan Toyota Great Corolla tipe 4A-FE. Rangkaian thermostat terdapat pada bagian bawah yang terdiri dari thermostat, relay, dan saklar magnet sedangkan rangkaian blower terdapat di bagian atas yang terdiri dari motor blower, resistor (tahanan), dan saklar blower. 


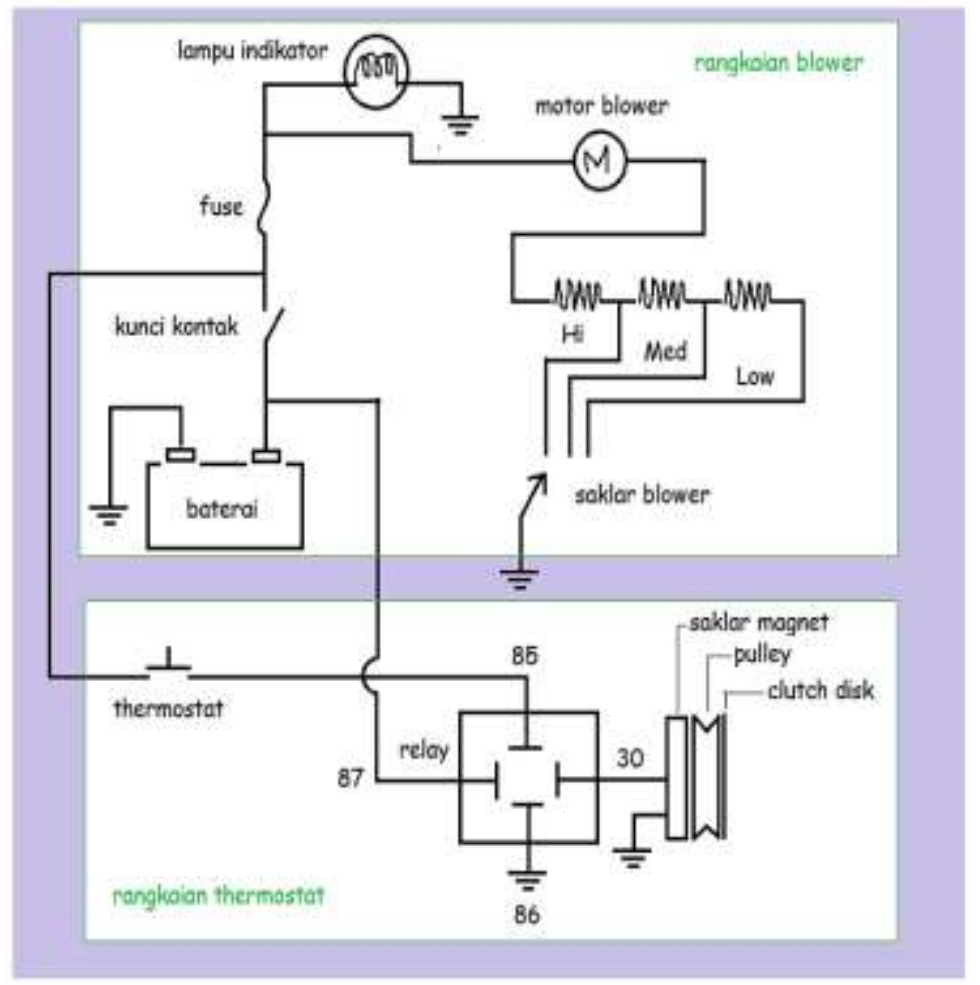

Gambar 2. Rangkaian Sistem Kelistrikan AC [8]

\subsection{Metode Penelitian}

Metode Penelitian yang digunakan dalam penelitian ini adalah dengan melalukan analisis prinsip kerja dan cara kerja pada Sistem AC Mobil Toyota Great Corolla tipe 4AFE. Kemudian mengidentifikasi fungsi dan cara kerja masing-masing komponennya agar dapat dirancang skema siklus dari sistem AC tersebut. Selanjutnya dilakukan analisis pada siklus sistem AC tersebut dan penjelasan tiap-tiap proses dalam siklusnya. Metode ini bertujuan untuk memudahkan dalam mengetahui cara perawatan dan proses identifikasi kerusakan pada sistem AC kendaraan.

Metode yang kedua adalah dengan langkah troubleshooting yaitu dengan memeriksa komponen - komponen dengan alat ukur tertentu yang sesuai untuk menentukan langkah perawatan (maintenance) dan perbaikan (service). Hasil pengukuran komponen - komponen menggunakan alat ukur feeler gauge dan multimeter dicocokkan dengan standar yang ada di dalam manual book atau buku manual pedoman reparasi atau servis Toyota Great Corolla tipe 4A-FE [8]. Jika sesuai dengan standard maka komponen - komponen tersebut masih dalam kondisi baik, namun jika tidak sesuai dengan standar atau di luar rentang atau interval batas standar maka komponen tersebut dalam kondisi yang buruk. Untuk kondisi komponen yang dalam kondisi buruk, perlakuannya ada dua metode yaitu dengan cara diperbaiki jika memungkinkan untuk diperbaiki dan diganti dengan komponen yang baru jika tidak dapat diperbaiki.

\section{HASIL DAN PEMBAHASAN}

\subsection{Kompresor}

Pemeriksaan yang dilakukan pada kompresor adalah dengan melakukan pembongkaran terlebih dahulu kemudian melakukan pemeriksaan pada beberapa komponen sebagai berikut: 
1. Kondisi bearing pada dudukan rumah bearing dalam kondisi baik dan belum mengalami keausan yang telah diukur menggunakan feeler gauge seperti yang terlihat pada Gambar 3.
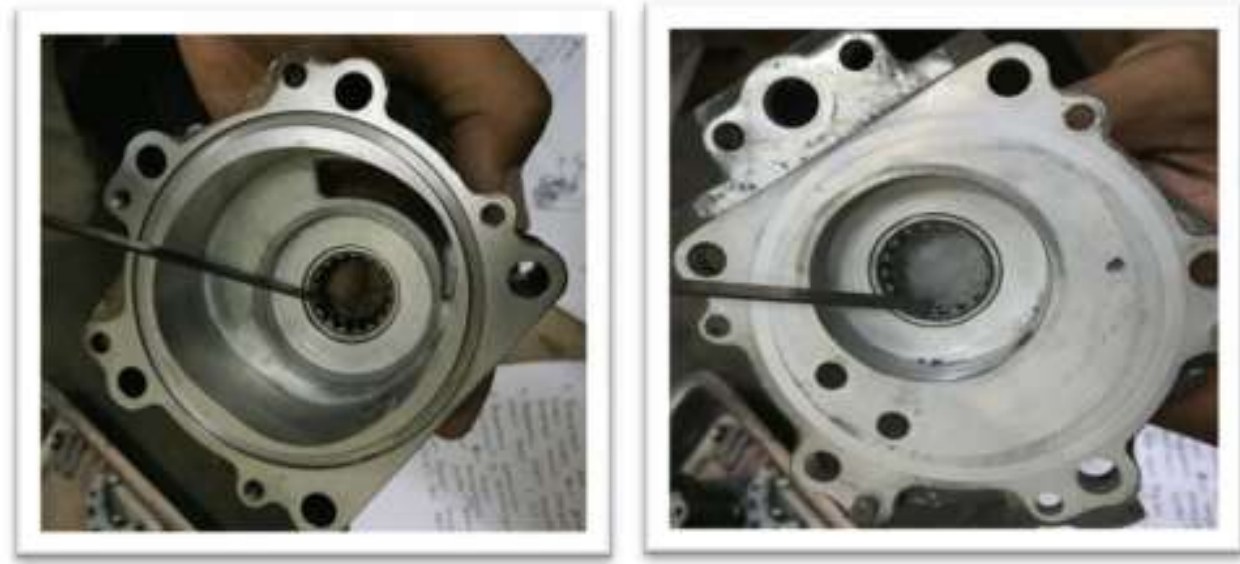

Gambar 3. Pemeriksaan Bearing Kompresor AC

2. Kondisi bilah atau through vane pada Gambar 4 masih baik dan tidak terdapat goresan atau keausan.
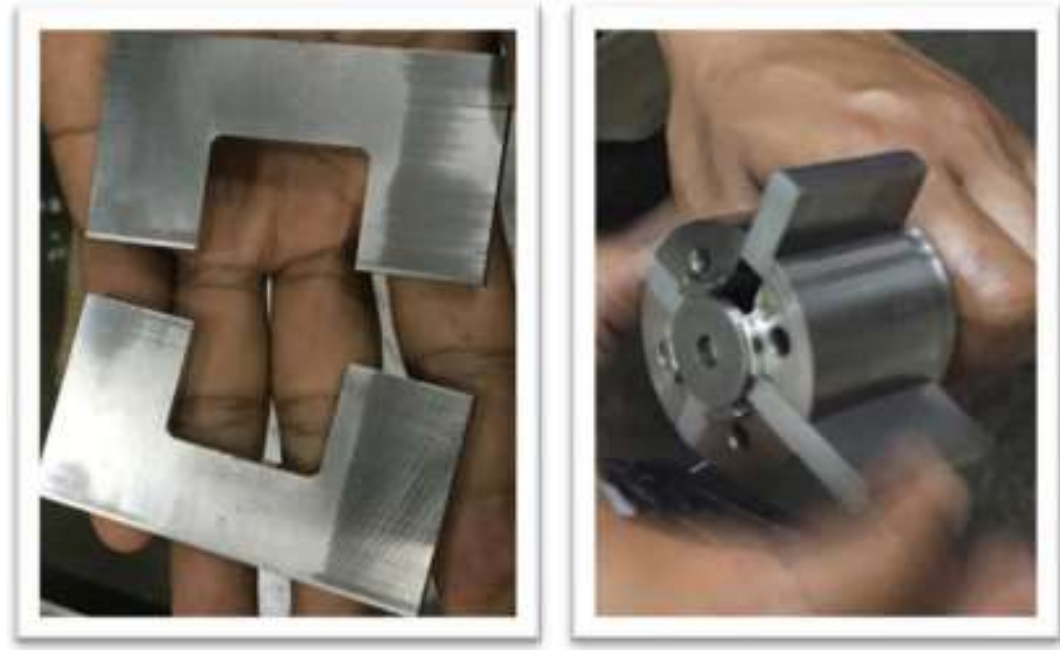

Gambar 4. Pemeriksaan Through Vane dan Rotor

3. Pemeriksaan celah through vane dengan dinding rumahnya yang diperlihatkan Gambar 5 di bawah ini sebesar $0,5 \mathrm{~mm}$, sesuai dengan standard pada buku manual pedoman reparasi atau servis Toyota Great Corolla tipe 4A-FE. Kemudian secara visual pemeriksaan yang dilakukan juga mengindikasikan bahwa komponen tersebut dalam kondisi yang baik dan tidak terdapat goresan.

4. Pemeriksaan seal keramik (Gambar 5) pada rumah kompresor untuk poros rotor masih dalam kondisi baik. Secara visual tidak tampak adanya keretakan, goresan, keausan, dan karet penahan masih elastis dan fleksibel. 

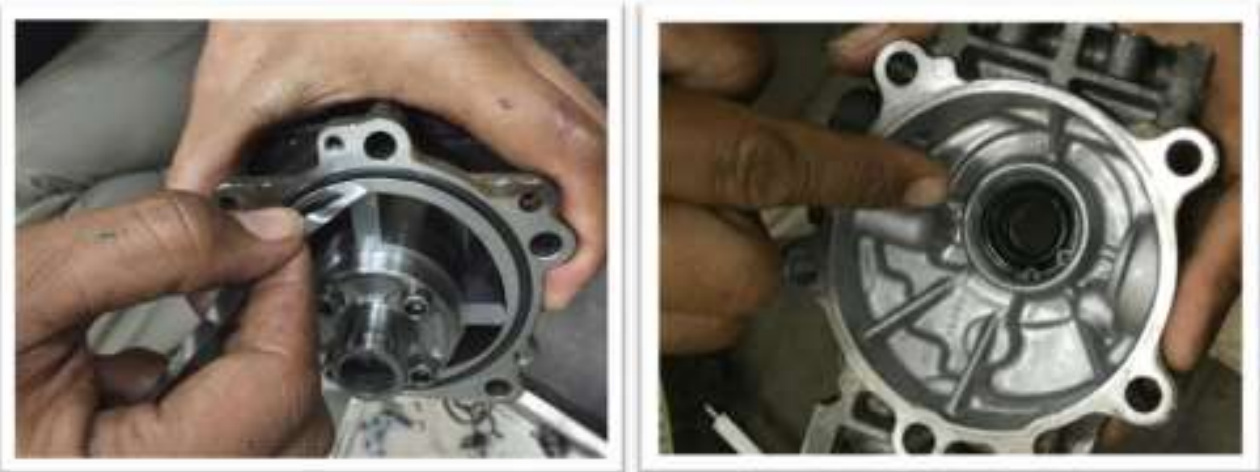

Gambar 5. Pemeriksaan Celah Vane dengan Dinding Rumah Kompresor dan Seal Keramik

5. Pemeriksaan nilai tahanan koil kopling magnetik dengan multimeter (Gambar 6) diperoleh 3,9 Ohm (dengan standar 3,75 $\pm 0,2 \mathrm{Ohm}$ ). Oleh karena itu sudah sesuai standar dan komponen dalam kondisi yang baik.

6. Pemeriksaan celah kopling magnet menggunakan feeler gauge (Gambar 6) diperoleh $0,5 \mathrm{~mm}$ (dengan standar 0,3-0,6 $\mathrm{mm}$ ). Sehingga komponen tersebut masih dalam kondisi yang baik.
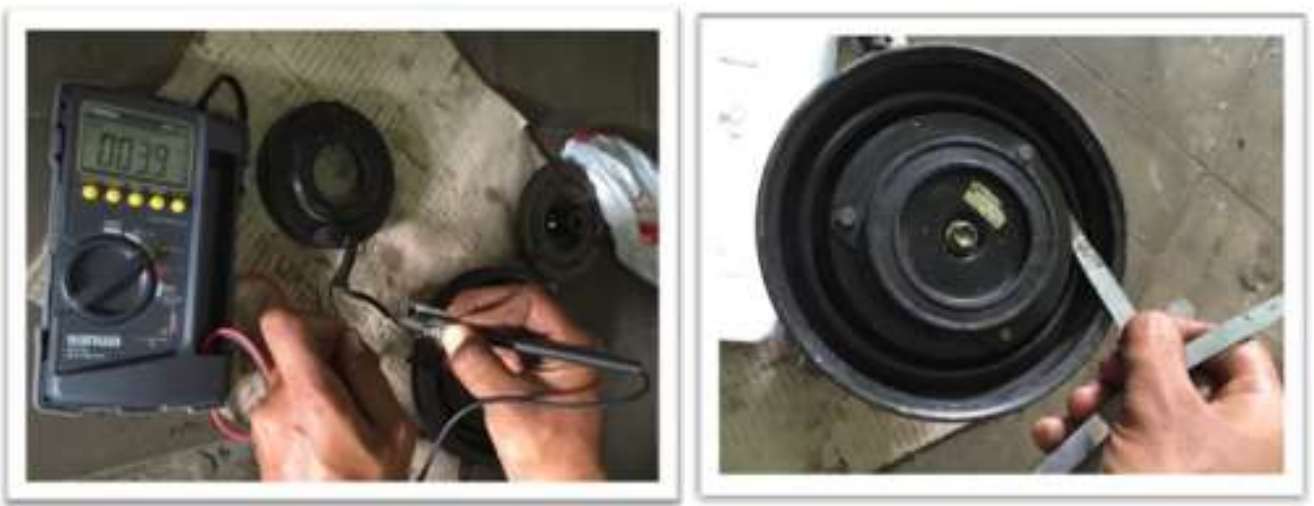

Gambar 6. Pemeriksaan nilai tahanan kumparan kopling magnetic dan celah kopling magnetic

\subsection{Katup Ekspansi}

Pada pemeriksaan komponen ini (Gambar 7) tidak ditemukan kerak dan kotoran sehingga katup ekspansi dalam kondisi yang baik. Katup ekspansi/ expansion valve yang ditunjukkan Gambar 7 terletak dekat dengan evaporator. 


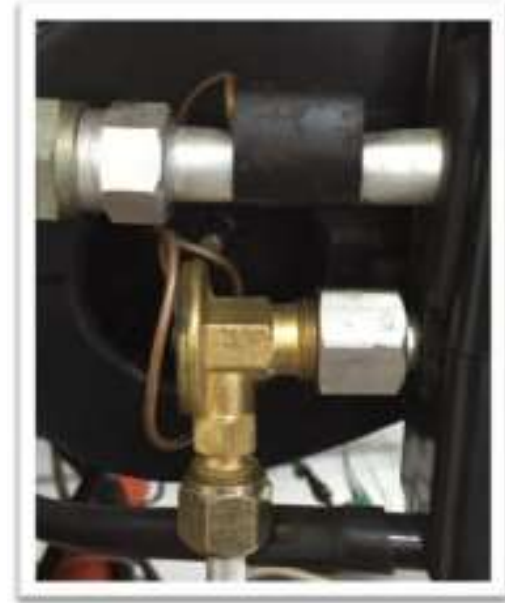

Gambar 7. Katup Ekspansi/ Expansion Valve

\subsection{Evaporator}

Pemeriksaan evaporator (Gambar 8) dilakukan dengan alat ukur multimeter diantaranya adalah sebagai berikut:

1. Hasil nilai tahanan pada instalasi blower pada tiga varian kecepatan yaitu posisi low 2,6 $\mathrm{Ohm}$, posisi medium $0,7 \mathrm{Ohm}$, dan posisi high $0 \mathrm{Ohm}$. Nilai tahanan pada motor blower sebesar $4 \mathrm{Ohm}$. Semua pemeriksaan masih berada dalam standard sehingga komponen tersebut masih dalam kondisi baik.

2. Hasil untuk kecepatan motor blower telah sesuai dengan kecepatannya masing masing.

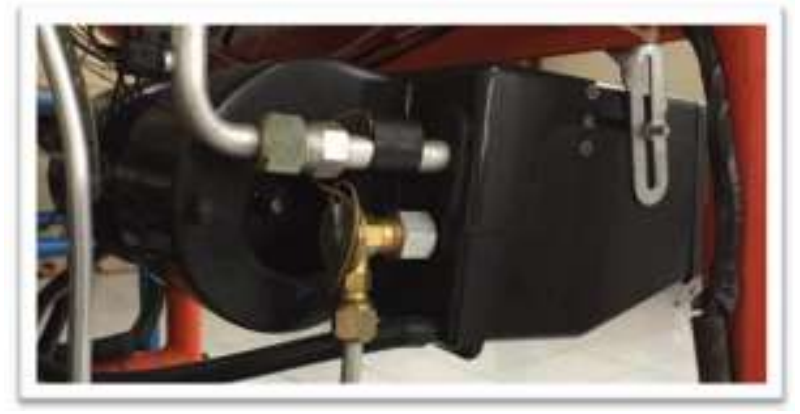

Gambar 8. Evaporator

\section{KESIMPULAN}

Semua komponen dalam sistem AC pada Mobil Toyota Great Corolla Tipe 4A-FE yang dijadikan sampel penelitian ini masih dalam kondisi yang baik. Hasil pengukuran diperoleh masih dalam batas servis atau masih dalam rentang standar berdasarkan buku manual Toyota Great Corolla Tipe 4A-FE. Oleh karena itu tidak ditemukan permasalahan pada sistem AC tersebut dan dapat disimpulkan bahwa kondisi sistem AC pada Mobil Toyota Great Corolla Tipe 4A-FE tersebut masih dalam kondisi normal dan layak untuk digunakan. Tidak dilakukan langkah perbaikan pada Sistem AC ini hanya saja dilakukan perawatan berkala untuk memastikan semua komponen dalam kondisi normal. 


\section{UCAPAN TERIMA KASIH}

Terimakasih kepada Program Studi Teknologi Mesin, Program Vokasi, Universitas Muhammadiyah Yogyakarta yang telah memfasilitasi laboratorium dan peralatan untuk penelitian ini.

\section{DAFTAR PUSTAKA}

[1] D. Kristanto and T. Leephakpreeda, "Sensitivity Analysis of Energy Conversion for Effective Energy Consumption, Thermal Comfort, and Air Quality within Car Cabin," Energy Procedia, vol. 138, pp. 552-557, 2017, doi: 10.1016/j.egypro.2017.10.158.

[2] S. Hermawan and R. Novianto, "Trouble Shooting Sistem Air Conditioner ( AC ) Pada Trainer AC Mobil,” Surya Tek., vol. 1, no. 1, pp. 26-33, 2017.

[3] S. Harianto, A. B. Setiawan, and A. P. Sari, "Studi Tentang Penggunaan Metode Scanning Pada Sistem Telemetri Pendeteksi Kerusakan Air Conditioner Kendaraan," Elektrika, vol. 01, no. 01, pp. 47-51, 2017.

[4] S. Harianto, A. B. Setiawan, and A. P. Sari, "Sistem Telemetri Pendeteksi Dini Kerusakan Air Conditioner Kendaraan Dengan Metode Scanning," in Prosiding SNATIF ke-4 Tahun 2017, 2017, pp. 97-103.

[5] A. Halim, D. Aviva, F. Backrie, and Mangkona, "Design of Diagnostic Tools Heavy Equipment Valve Air Conditioning (HVAC) Based Microcontroller for Troubleshooting Air Conditioner on Machine Heavy Equipment," in International Conference on Science, Technology, and Environment, 2020, pp. 113-121.

[6] F. Fahmizal, T. R. Orlando, B. B. Murti, M. Budiyanto, and A. Mayub, "Kendali Logika Fuzzy pada Sistem Electronic Control Unit (ECU) Air Conditioner Mobil," J. Teknol. Inf. dan Ilmu Komput., vol. 6, no. 1, pp. 25-31, 2019, doi: 10.25126/jtiik.2019611045.

[7] W. Fahmi and A. G. W, "Rekayasa Rancang Bangun Trainer Sistem Kelistrikan Ac Mobil Daihatsu," Jrm, vol. 2, no. 2, pp. 41-45, 2015.

[8] T. M. Corporation, "TOYOTA 4A-FE, 4A-GE," in Toyota Great Corolla tipe 4AFE Repair Manual, 1989, pp. 1-228. 